donor site: circumference and area ratios of deep tissue to thigh. Microsurgery. 2013;33(4):270-274. doi:10.1002/micr.22080

8. Visconti G, Salgarello $\mathbf{M}$. Anteromedial thigh perforator-assisted closure of the anterolateral thigh free flap donor site. Journal of Plastic Reconstructive \& Aesthetic Surgery. 2013:66(7):e189-e192.

doi:10.1016/j.bjps.2013.02.021

\title{
KHỚP HÁNG CÁN NGẮN: PHÂN LOẠI VÀ KẾT QUẢ PHẪU THUẬT
}

\section{TÓM TẮT}

Mục tiêu: Cập nhật, hệ thống lại phân loại cũng như kết quả trên lâm sàng của khớp háng cán ngắn. Đối tượng và phương pháp: Đối tượng của chúng tôi là các bài báo trên dữ liê̂u Pubmed, qua các tài liêu tìm được tiến hành phân tích, phân loại khớp háng cán ngắn và tổng hợp kết quả điều trị phẫu thuâtt theo từng phân loại đó. Kết quả: Có hai phân loại được sử dung nhiêuu hơn cả đó là phân loai theo Khanuja H.S. (4 loại) và phân loại theo Hội nghiên cứu và phẫu thuât khớp (Joint implant surgery and research foundation-JISRF) 2 loại: Nhóm cố định vùng cổ và nhóm cố đinh vùng hành xương. Tai Viêt Nam chỉ mới có khớp háng cán ngắn Spiron. Kểt luận: khớp háng cán ngắn được phân loại tùy theo hình dáng, vị trí cố định và mức độ bảo tồn xương. Kết quả theo dõi chủ yếu tập trung trong thời gian ngắn hạn và trung hạn và tương đối khả quan.

Từ khóa: Khớp háng cán ngắn, phân loại, kết quả

\section{SUMMARY \\ SHORT-STEM HIP PROSTHESES: \\ CLASSIFICATION SYSTEM AND TREATMENT OUTCOMES}

Objective: An update on the classification systems and treatment outcomes of short-stem hip prostheses. Materials and methods:From electronic database of PubMed, relevant articles involving classification and treatment outcomes of different types of short-stem hip prostheses were identified and organized. Results: The most popular classification systems were developed byKhanuja H.S. (four categories) and Joint implant surgery and research foundation (JISRF) (two categories: neck-stabilized and metaphyseal-stabilized). In Vietnamese literature, the Spiron prosthesis was the only femoral short-stem with published studies. Conclusions: Short-stem hip prostheses were classified according to their morphology, fixation principles andpreservation ofproximal bone stock. The short to mid-term outcomes published by authors have been promising.

Keyword: Short-stem hip prostheses,classification systems, outcomes.

*Bệnh viện TUQQ 108,

Chiu trách nhiệm chính: Mai Đức Thuận

Email: thuanmd108@gmail.com

Ngày nhận bài: 16/7/2021

Ngày phản biên khoa họ: 10/8/2021

Ngày duyệt bài: 27/8/2021

\section{I. ĐĂT VẤN ĐỀ}

Nếu khớp háng toàn phần ra đời vào những năm của thâp niên thứ 4 thì mãi đến thập niên thứ 8 của thế kỷ thứ XX khớp háng cán ngắn mới ra đời, đánh dấu bằng việc chế tạo thành công của khớp bảo tồn xương Thrust-Plate [1]..

Có nhiều thuật ngữ được sử dụng để nói đến khớp cán ngắn như: Khớp bảo tồn xương, khớp có kích thước ngắn, khớp cố định ở vùng cổ. Vì không có định nghĩa chính xác nên khớp cán ngắn được phân loại dựa theo mức độ bảo tồn xương, vị trí cố định và hình dáng cấu tạo. Vị trí cố định của khớp cán ngắn thường ở cổ xương đùi hoặc ở hành xương [2]. Tuy nhiên, một vài khớp được cố định mở rộng xuống dưới mấu chuyển bé. Phần cổ xương đùi thường được bảo tồn một phần hoặc toàn bộ [2]. Sau hơn 30 năm sau, lần đầu tiên Việt Nam mới ứng dụng thành công khớp háng cán ngắn. Tuy nhiên ở Việt Nam khớp háng cán ngắn chưa thực sự được quan tâm đúng mực và sự hiểu biết về các loại khớp háng cán ngắn còn rất hạn chế, việc phân loại và kết quả phẫu thuật còn nhiều tranh cãi. Xuất phát từ lý do trên chúng tôi cập nhật, hệ thống lại phân loại cũng như kết quả trên lẩm sà̀ng của khớp háng cán ngắn.

\section{II. ĐỐI TƯợNG VÀ PHƯƠNG PHÁP NGHIÊN CỨU}

- Đối tượng của chúng tôi là các bài báo trên dữ liệu Pubmed. Từ khóa đầu tiên để tìm kiếm là: "khớp háng cán ngắn", sau đó tài liệu được lọc lại bằng từ khóa thứ 2: "Phân loai khớp háng cán ngắn" hoặc" Kết quả thay khớp háng cán ngắn".Chúng tôi đã tìm được nhiều tài liệu theo cách trên và qua sàng lọc lại chọn được 20 tài liêu, trong đó có 2 tài liệu độ tin cậy mức II, 7 tài liệu độ tin cậy mức III, 11 tài liệu độ tin cậy mức IV, các tài liệu này có thời gian theo dõi trên lâm sàng ít nhất 2 năm.

- Nhiều nhất là các tài liệu nói về khớp cán ngắn cong, có 4 tài liệu nói về khớp háng cán ngắn cố định vùng cổ, 16 tài liệu về các loại cán ngắn cong, 6 tài liều về khớp cán ngắn cố định vùng hành xương và có phần lồi ra lấp đầy vùng 
mấu chuyển lớn, có 4 tài liệu khớp cán ngắn vừa khít vùng hành xương.

- Qua các tài liệu tìm được tiến hành phân tích các cách phân loại khớp háng cán ngắn, căn cứ để phân loại khớp háng cán ngắn và tổng hợp kết quả điều trị phẫu thuật theo từng phân loại đó.

\section{KẾT QUẢ NGHIÊN CỨU VÀ BÀN LUÂNN}

Hơn 30 năm qua, đã có nhiều khớp háng cán ngắn ra đời, do đó cũng có nhiều cách phân loại khác nhau. Có hai phân loại được sử dụng nhiều hơn cả đó là phân loại theo Khanuja H.S. [2] và phân loại theo Hội nghiên cứu và phẫu thuật khớp (Joint implant surgery and research foundation-JISRF) - Tổ chức này được thành lập từ năm 1971 tại Hoa Kỳ [1].

3.1. Phân loại theo Khanuja H.S. Năm 2014, dựa vào phẩn xương bị cắt bỏ (Hình 3.1) và vị trí cố định cán khớp, Khanuja H.S. [2] chia khớp cán ngắn ra làm 4 nhóm:

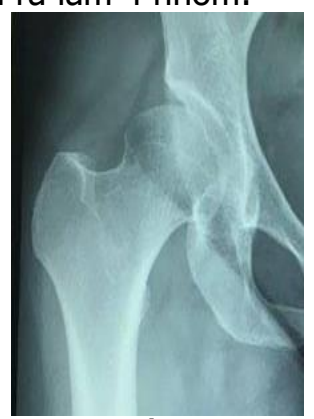

Hình 3.1. Đường cắt xương của 4 nhóm khớp cán ngắn theo Khanuja H.S [2].

- Nhóm 1 (Collum): Cán khớp cố định vùng cổ, đường cắt xương sát chỏm (Đường 1 - Hình 3.1), toàn bộ cổ xương đùi được giữ lại.

- Nhóm 2 (Partial collum): Cán khớp cố định vùng calca hoặc cố định thêm vùng mặt ngoài đầu trên xương đùi, đường cắt xương giữa cổ (Đường 2 - Hình 3.1), một phần cổ xương đùi được giữ lại.

- Nhóm 3 (Trochanter sparing): Cán khớp cố định vùng hành xương, đường cắt xương giữ lại toàn bộ vùng liên mấu chuyển (Đường 3 ).

- Nhóm 4 (Trochanter harming): Cán khớp cố định đầu trên xương đùi, đường cắt cổ xương đùi như thay khớp háng cán dài (Đường 4).

Nhiều tác giả đi theo phân loại này vì nó ngắn gọn, dễ nhớ. Đây là phân loại chủ yếu dựa vào mức độ bảo tồn xương.

\subsection{Phân loai theo JISRF}

Dựa vào vị trí cố định của cán khớp năm 2015, Hiệp hội nghiên cứu và phẫu thuật khớp Hoa kỳ [1] đã chia khớp háng nhân tạo thành 4 nhóm (Hình 3.2):
- Nhóm 1: Cán khớp cố định vùng chỏm (Head stabilized). Gồm 2 phân nhóm:

+ 1a: Khớp háng bề mặt (Hip resurfacing).

+ 1b: Cán khớp giữa chỏm (Mid-Head stem).

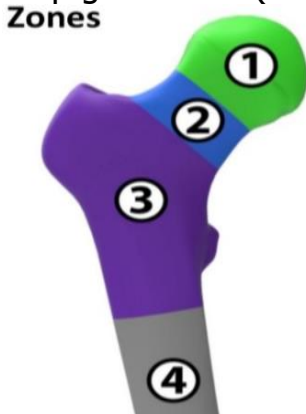

Hình 3.2. Vị trí cố định của các nhóm khớp*Nguồn: Theo McTighe T. (2015) [1]

- Nhóm 2: Cán khớp cố định vùng cổ (Neck stabilized). Gồm 3 phân nhóm:

+ 2a: Cán ngắn cong (short curved stems).

+ 2b: Cán ngắn phù hợp với phía ngoài của hành xương (Short lateral engaging stem).

+ 2c: Cán ngắn chỉ ở cổ xương đùi (Neck plugs or neck only).

- Nhóm 3: Cán khớp cố định vùng hành xương (Metaphyseal stabilized). Gồm 2 phân nhóm:

+ 3a: Cán khớp hình côn (Taper stem).

$+3 \mathrm{~b}$ : Cán khớp vừa khít vùng hành xương (Bulky/fit and fill stems).

- Nhóm 4: Cán khớp thông thường (cố định ở thân xương hoặc hành xương) (Conventional metaphyseal/Diaphyseal stabilized).

Theo McTighe T. các khớp thuộc nhóm 2, nhóm 3 là khớp háng cán ngắn [1]. Đây là cách phân loại cán ngắn dựa vào vị trí cố định của cán khớp, tuy chỉ có 2 nhóm là nhóm cố định vùng cổ và nhóm cố định vùng hành xương nhưng trong 2 nhóm lớn được chia thành nhiêuu phân nhóm nhỏ dựa và vị trí cố định và hình dáng khớp. Các phân loại này tương đối chi tiết và cụ thể tuy nhiên khó nhớ hơn cách phân loại của Khanuja H.S [2].

3.2.1. Khớp cán ngắn cố định vùng cổ xương đùi (Nhóm 2-JISRF)

3.2.1.1. Cán ngắn cong (Nhóm 2a). Các khớp thuộc nhóm này (Hình 3.3) có cán thuôn cong theo góc cổ thân xương và cổ xương đùi được bảo tồn toàn bộ. Nhóm cán khớp cong được cố định tại cổ xương đùi với nhiều mẫu thiết kế như: Khớp CFP (Collum femoris preserving) (Hình 3.3A), Nanos (Hình 3.3B), MSA (Muscle sparing approach) (Hinh 3.3C), TSI (Tissue sparing implant) (Hình 3.3D), Corin Mini Hip (Hình 3.3E) [7]. 

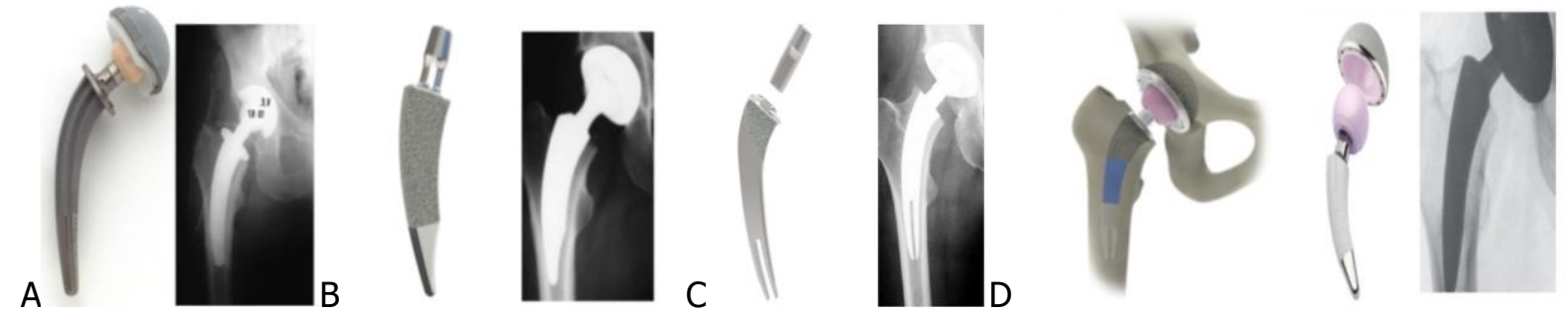

Hình 3.3. Các khớp cán ngắn cong*Nguồn: Theo McTighe T. (2015) [1]

Có 24 nghiên cứu trên 1394 khớp háng thuộc nhóm này đã sử dụng. Khớp CFP (Collum femoris preserving) là khớp cán ngắn cong có thời gian theo dõi dài nhất trên y văn [1].Theo Kendoff $D$. [3], Pipino F., Nowak M., Ghera S. [4], tỷ lệ còn tồn tại của nhóm khớp này là $99,3 \%$ (từ $96,6 \%$ đến $100 \%$ ) với thời gian theo dõi trung bình 6,3 năm (từ 2 - 17 năm).

Điểm Harris của 761 khớp háng được thay là 93 điểm (từ 90 đến 99 điểm). Trong 984 khớp của 9 báo cáo tỷ lệ gãy xương trong mổ dao động từ $0 \%$ đến $13,3 \%$ (trung bình 2,6\%). Trong 432 khớp háng được theo dõi tỷ lệ cán khớp không thẳng trục trung bình là 21,6\% (từ $5,2 \%$ đến $60 \%$ ). Trong bốn nghiên cứu liên quan đến 369 khớp, tỷ lệ tụt cán hơn $2 \mathrm{~mm}$ dao động từ $0 \%$ đến $11 \%$. Tỷ lệ trung bình cán khớp đặt chưa đúng vị trí là $11 \%$ (từ $6,3 \%$ đến $20 \%$ ). Tỷ lệ đau đùi trung bình trong bảy nghiên cứu với 599 khớp háng là $2 \%$ (từ $0 \%$ đến $11 \%$ ) và hiện tượng tiêu xương quanh đầu trên của 414 cán khớp được theo dõi là $35 \%$ (từ $5,2 \%$ đến 66\%) [2]. Theo Kaipel M. [5] các khớp nhóm 2a cần phải chuẩn bị trước mổ (template) tốt và lựa chọn khớp chính xác để hạn chế các biến chứng sau mổ.

3.2.1.2. Cán ngắn phù hợp với phía ngoài của hành xương(Nhóm 2b)

Đây là một loại cán khớp cố định ở hành xương, có phần lồi ra phía ngoài lấp đầy vùng mấu chuyển lớn (Hình 3.4). Nhóm này thường có thiết kế hình nón hoặc hình thang phù hợp với giải phẫu xương đùi tại vị trí khớp cố định. Nó giúp chuyển tải lực đều đển calcar và phía ngoài của đầu trên xương đùi. Khanuja H.S. [2] đã tổng kết 6 nghiên cứu trên 724 khớp thuộc nhóm này và thấy rằng tỷ lệ tồn tại của khớp là $100 \%$ với thời gian theo dõi trung bình 4,2 năm (dao động 2,2 - 5,6 năm). Điểm Harris sau mổ dao động từ 86 - 96 điểm (trung bình 90 điểm). Trong 595 khớp ở trên, hiện tượng lệch trục trên mặt phẳng đứng ngang (coronal plane malalignment) là $9,5 \%$ (dao động từ 5,4\% $24,3 \%$ ), tỷ lệ gãy xương trong mổ là $1 \%$ (dao động $0-2,4 \%$ ), tỷ lệ lún cán hơn $2 \mathrm{~mm}$ là $0,2 \%$ (dao động $0-0,8 \%$ ), tỷ lệ sai khớp trung bình là 1,4\% (dao động từ 0 - 2,4\%).

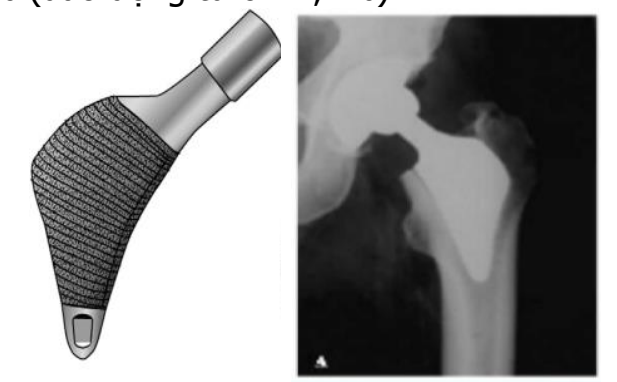

Hình 3.4. Khớp cán ngắn cố định vùng hành xương (khớp Proxima)[2]

Nhóm này thường có thiết kế hình nón hoặc hình thang phù hợp với giải phẫu xương đùi tại vị trí khớp cố định. Nó giúp chuyển tải lực đều đến calcar và phía ngoài của đầu trên xương đùi. Khanuja H.S. [2] đã tổng kết 6 nghiên cứu trên 724 khớp thuộc nhóm này và thấy rằng tỷ lệ tồn tại của khớp là $100 \%$ với thời gian theo dôi trung bình 4,2 năm (dao động 2,2 - 5,6 năm). Điểm Harris sau mổ dao động từ 86 - 96 điểm (trung bình 90 điểm). Trong 595 khớp ở trên, hiện tượng lệch trục trên mặt phẳng đứng ngang (coronal plane malalignment) là 9,5\% (dao động từ $5,4 \%-24,3 \%)$, tỳ lệ gãy xương trong mổ là $1 \%$ (dao động $0-2,4 \%$ ), tỷ lệ lún cán hơn $2 \mathrm{~mm}$ là $0,2 \%$ (dao động $0-0,8 \%$ ), tỷ lệ sai khớp trung bình là $1,4 \%$ (dao động từ 0 - 2,4\%).

3.2.1.3. Cán khớp chi ơ phần cố xương đùi (Nhóm 2c). Nhóm 2c điển hình là các khớp: Cut (Hình 3.5A), khớp Silent (Hình 3.5B, khớp Trimosis (Hình 3.5C), khớp Trials (Hình 3.5D), khớp Spiron (Hình 3.5E). Đây là các khớp được đặt và cố định ở vùng cổ xương đùi, đường cắt xương dưới chỏm (sát chỏm).

Khớp Silent (Hình 3.5B)được thiết kễ dạng thuôn, với thiết kế này khớp có thể nằm trọn trong phần cổ xương đùi. Đây là thiết kế dành cho các bệnh nhân trẻ, còn hoạt động nhiêu. Loại khớp này được hy vọng có nhiều lợi ích hơn khớp háng bề mặt. Năm 2012, Waller $C$. đã thay khớp háng Silent cho 14 bệnh nhân (với 15 khớp 
háng), theo dõi sau 2 năm điểm Harris trước mổ trung bình là 52, sau mổ là 97,4 (trong đó 10 bệnh nhân có điểm Harris là 100 điểm), chỉ có 1

bệnh nhân bị biến chứng viêm tắc tĩnh mạch sâu [2].

$\boldsymbol{A}$
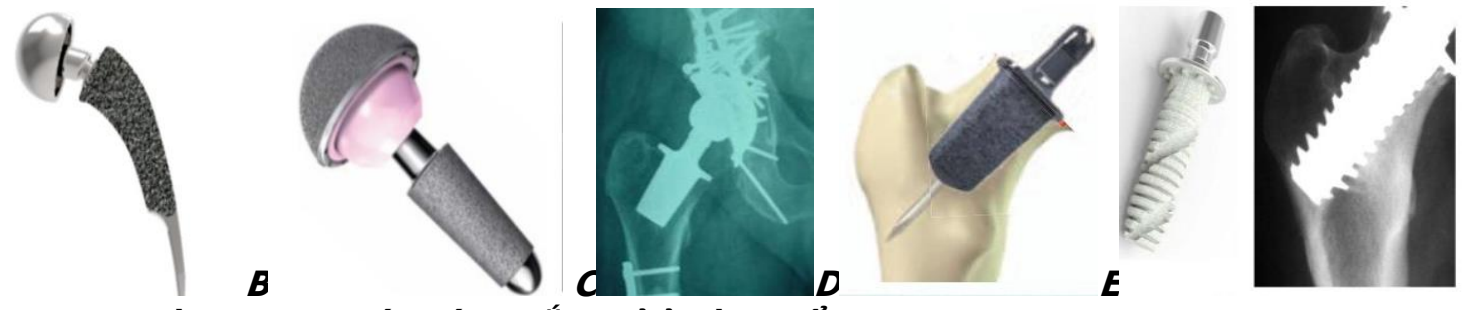

Hình 3..5. Khớp cán ngắn chỉ ở vùng cổ theo McTighe T. (2015) [1]

Năm 1989, tại Cộng hòa liên bang Đức, Birkenhaur B. đã nghiên cứu và chế tạo ra khớp cán ngắn Spiron (Hình 3.5E). Khớp được ứng dụng lần đâu vào năm 2001 [6]. Từ tháng 02/2001 đến tháng 04/2003, tại bệnh viện DRK Hospital Neuwied (Cộng hòa liên bang Đức), Birkenhauer B. [6] đã thay 38 khớp háng nhân tạo Spiron cho 34 bệnh nhân, 4 trường hợp thay cả 2 bên. Trong đó có $20 \mathrm{BN}$ nam, $14 \mathrm{BN}$ nữ, tuổi trung bình 60,1 (43 - 73 tuổi). Điểm Harris trước phẩu thuật là 51 điểm (24 - 76 điểm). Sau mổ 1 năm kiểm tra được 20 bệnh nhân, điểm Harris tăng lên 94 điểm (86 - 100 điểm) [6].

3.2.2. Khớp cán ngắn cố định vùng hành xương đâu trên xương đùi (Nhóm 3- JISRF)

3.2.2.1. Cán khớp hình côn (Nhóm 3a). Nhóm này bao gồm các khớp như: Khớp MayO (Hình 3.6A), khớp Metha (Hình 3.6B), khớp Fitmore (Hình 3.6C), khớp Taperloc (Hình 3.6D), khớp Tri-lock (Hình 3.6E). Các khớp thuộc nhóm này có hình côn, thuôn, chém cạnh, đối xứng và được cố định ở hành xương.
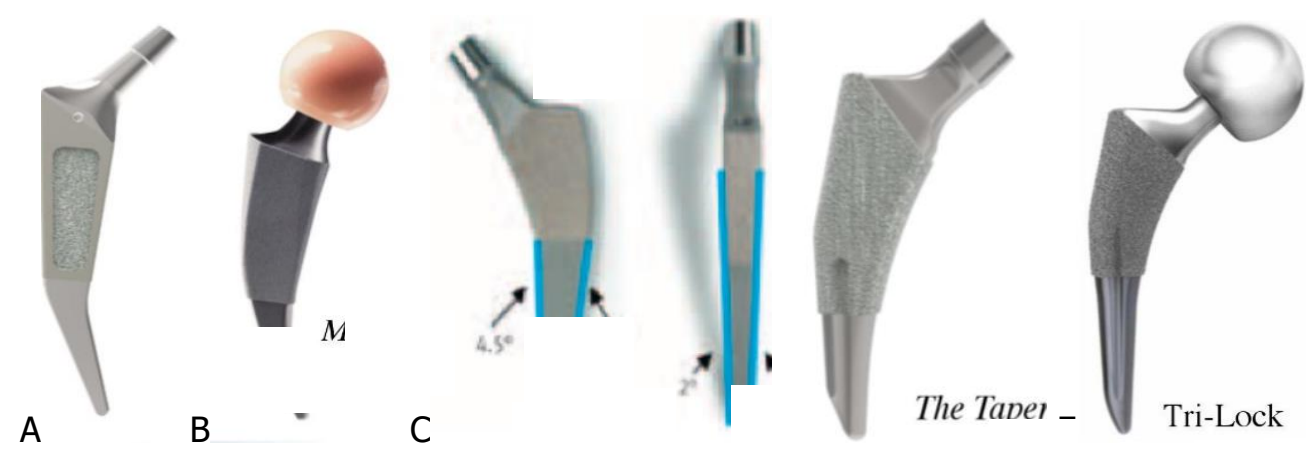

Hình 3.6. Các cán khớp hình côn theo McTighe T. (2015) [1].

Có 1123 khớp háng thuộc nhóm này đã được nghiên cứu. Theo Wittenberg R. [7], Espehaug B., Khanuja H. S. [2] tỷ lệ còn tồn tại của nhóm khớp này là $99,4 \%$ (dao động từ $98-100 \%$ ) trên 548 khớp có thời gian theo dõi trung bình 35 tháng (từ 2-5 năm). Điểm Harris dao đông từ 90,4-97,6 điểm (trung bình 94 điểm). Tỷ lệ gãy xương trong mổ của 390 khớp háng thuộc nhóm này dao động từ $0 \%$ đến $2,7 \%$ (trung bình $1,5 \%)$, trong 548 khớp háng nhóm này được theo dõi tỷ lệ lún cán trung bình lớn hơn $2 \mathrm{~mm}$ là 4,2\% (từ 0\% đến 14,6\%). Wittenberg R. [7] theo dõi 250 khớp cán ngắn Metha (thời gian trung bình 59 tháng), hiện tượng tiêu xương quanh phần trên cán khớp là 2,5\%.

Theo Morrey B.F. [8] tỷ lệ còn tồn tại của 503 khớp thuộc nhóm này là $98,6 \%$ (dao động từ
$97,4 \%$ đến $100 \%$ ) với thời gian theo dõi trung bình 62 tháng (từ 24-94 tháng). Điểm Harris dao động từ 90-96 điểm (trung bình 93 điểm). Hiện tượng lệch trục trên mặt phẳng đứng ngang là $6,8 \%$ trong 49 khớp. Tỷ lệ gãy xương trong mổ là $4,4 \%$ (từ $0 \%$ đến $7,1 \%$ ) trong 440 khớp được theo dõi. Tỷ lệ đau đùi sau mổ trung bình là $1,6 \%(0 \%, 2 \%$, và $2,7 \%)$ của 250 khớp háng theo dôi trung bình 5 năm (từ 37 tháng - 78 tháng).

\subsubsection{Cán ngắn vừa khít vùng hành} xương (Nhóm 3b). Các khớp thuộc nhóm này có thể kể đến như khớp Balance (Hình 2.6A), khớp ABGII (Anatomique Benoist Gerard) (Hình 2.6B), khớp Revelation (Hình 2.6C). Các khớp thuộc nhóm này cấu tạo đầu trên của cán to, lấp đầy và cố định chặt ở vùng hành xương. 

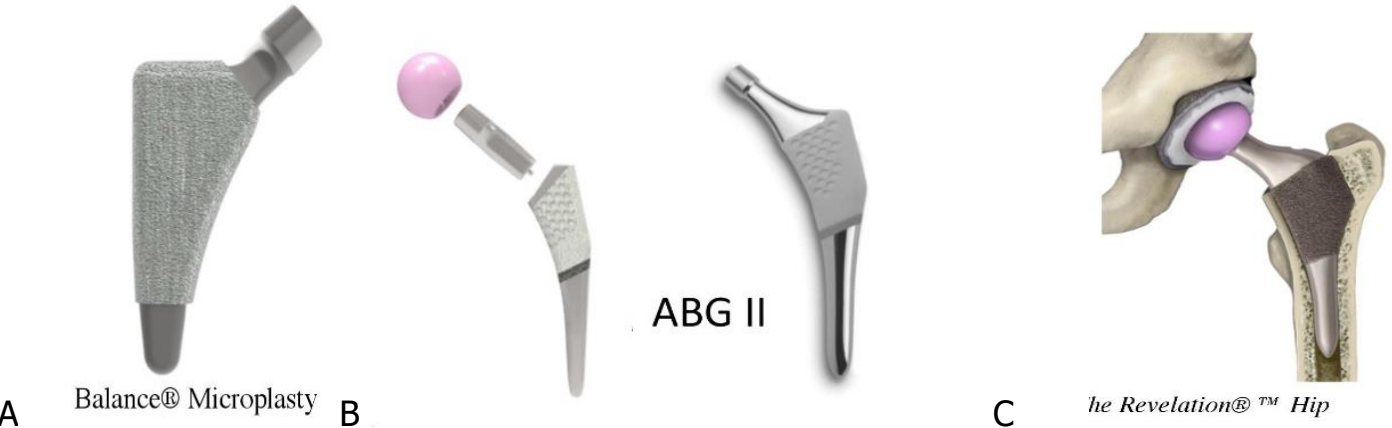

Hình 3.7. Các cán khớp lấp đây vùng hành xương theo McTighe T. (2015) [1]

Khớp ABG (Anatomique Benoist Gerard) II có 2 loại: Loại monoblock và modular (Hình 3.7B). Năm 2012, Dawson B. đã báo cáo kết quả nghiên cứu 212 khớp, thời gian theo dõi trung bình 74 tháng, khớp ABG II (loại monoblock) tỷ lệ tồn tại là $95,8 \%$, tổng cộng có 9 khớp phải thay lại (chiếm 4,2\%).

3.3. Tại Việt Nam. Việt Nam chỉ mới ứng dụng một loại khớp cán ngẳn-khớp Spiron được từ năm 2011. Khớp háng Spiron là khớp háng cán ngắn chỉ ở vùng cổ xương đùi thuộc nhóm 2c theo phân loại của JISRF

Tại Viện Chẩn thương Chỉnh hình - Bệnh viện Việt Đức, Bùi Hải Nam [9] đã đánh giá kết quả thay 60 khớp háng Spiron cho 50 bệnh nhân, tuổi trung bình 42,93, với thời gian theo dõi trung bình 21,31 tháng kết quả như sau: điểm VAS (Visual Analog Scales) trước mổ là 5,05, sau mổ giảm còn 1,35 ,điểm Harris trước mổ là 58,78 , sau mổ là 89,37 , sự khác biệt có ý nghĩa thống kê với $p<0.05$. Qua nghiên cứu tác giả đi đên nhân xét: thay khớp Spiron chỉ định phải chặt chẽ், chú ý đên lứa tuổi bệnh nhân, đo mật độ xương cổ xương đùi; phải lập kế hoạch trước mổ cụ thể và tác giả cũng cho rằng cần phải theo dõi kết quả trong thời gian dài hơn.

Đánh giá kết quả thay khớp háng toàn phần Spiron cho 72 bệnh nhân với 94 khớp, thời gian từ tháng 2/2012 đến tháng 8/2016,thời gian theo dõi trung bình 35,1 tháng tại Bệnh viện TƯQĐ 108 chúng tôi thấy: Điểm Harris trung bình trước phẫu thuật là 45,9, sau phẫu thuật là 92,1, tại thời điểm kiểm tra kết quả xa là 91,8 . Với cho kết quả rất tốt là: $76,7 \%$, tốt: 17,8\%, trung bình: 3,3\%, kém: 2,2\%.

\section{KẾT LUẦN}

Như vậy khớp háng cán ngắn được phân loại tùy theo hình dáng, vị trí cố định và mức độ bảo tồn xương. Các nghiên cứu về khớp háng cắn ngắn trên lâm sàng chưa nhiều và mới tập trung ở một số loại khớp nhất định. Kết quả theo dôi chủ yếu tập trung trong thời gian ngắn hạn và trung hạn. Kết quả ban đầu tương đối khả quan, Tuy nhiên cần nhiều công trình nghiên cứu với thời gian theo dõi dài để đánh giá độ bền của loai khớp này cũng như những biến chứng muộn có thể xảy ra. Với những bênh nhân trẻ có chỉ định thay khớp mà chất lượng xương còn tốt, khớp háng cán ngắn được kỳ vọng sẽ đem lại nhiều thay đổi trong tương lai.

\section{TÀI LIÊUU THAM KHẢO}

1. McTighe T., David S., Louis K. et al. (2015), "Short-stem designs for total hip arthroplasty: neck stabilized femoral components", Orthopaedic and Trauma Surgery, 64, pp. 823-849.

2. Khanuja H. S., Banerjee $S_{\text {., Jain }} D_{\text {. et al. }}$ (2014), "Short bone-conserving stems in cementless hip arthroplasty", The Journal of Bone and Joint Surgery American, 96(20), pp. 1742-1752.

3. Kendoff D., Citak M., Egidy C. et al. (2013), "Eleven-year results of the anatomic coated CFP stem in primary total hip arthroplasty", The Journal of Arthroplasty, 28(6), pp. 1047-1051.

4. Ghera S., Bisicchia S. (2013), "The collum femoris preserving stem: early results", Hip international, 23(1), pp. 27-32.

5. Kaipel M., Grabowiecki P., Sinz K. et al. (2015), "Migration characteristics and early clinical results of the Nanos short-stem hip arthroplasty", Wiener klinische Wochenschrift, 127(9-10), pp. 375-378.

6. Birkenhauer B., Kistmacher H., Ries J. (2004), "Conception and first results of the Spiron cementless femoral neck screw prosthesis", Orthopade, 33(11), pp. 1259-1266

7. Wittenberg R. H., Steffen R., Windhagen H. et al. (2013), "Five-year results of a cementless short-hip-stem prosthesis", Orthopedic Reviews, 5(1): e4, pp 1-22.

8. Morrey B. F., Adams R. A., Kessler M. (2000), "A conservative femoral replacement for total hip arthroplasty. A prospective study", The Journal of Bone and Joint SurgeryBritish, 82(7), pp. 952-958. 